\title{
Identifying Conversational Structures and Strategies between Guide and Foreign Guests in Transactional Negotiation of Tour (Transport) Service
}

\author{
1 Irsan Hambali \\ 1Universitas Muhammadiyah Mataram, Mataram, Indonesia \\ irsanhambali@gmail.com
}

\begin{tabular}{|c|c|}
\hline Article Info & bstract \\
\hline $\begin{array}{l}\text { Article History } \\
\text { Received: July 12, } 2018 \\
\text { Accepted: September 30, } \\
2018\end{array}$ & \multirow{2}{*}{$\begin{array}{l}\text { This article aimed to find conversational structure and strategies employed } \\
\text { by guides in transactional negotiation with foreign guests and find out the } \\
\text { best one, which latter becomes standardized conversational structures and } \\
\text { strategies in persuading and satisfying customers. This paper examined } \\
\text { structures of conversation with regard to Sinclair-Coulthard's Birmingham } \\
\text { model. This study is qualitative in nature, attempting to describe data, } \\
\text { represented in the form of words. During data collection, utterances were } \\
\text { recorded directly by a set of tape-recorders then transcribed into spoken } \\
\text { text. Later, the recorded data were analyzed using Sinclair Coulthard } \\
\text { analysis model of within or outside classroom discourse. The data were } \\
\text { analyzed in terms of the four discourse units: transaction, exchange, move, } \\
\text { and acts. Among these four units, exchange and move were mainly focused. } \\
\text { The result showed that the structure of guides' conversation in doing } \\
\text { transactional negotiation is somewhat the same. Starting from so - called } \\
\text { starter which consist of question and answer then transaction which } \\
\text { employed question and informing and the last is closing. There were } 3 \text { scripts } \\
\text { epitomized the result. The script } 1 \text { and } 2 \text { merely focused on price without } \\
\text { explaining the itinerary and car services extensively. The script } 3 \text { showed the } \\
\text { success of transaction, that is how guide employed strategic communication } \\
\text { in transactional negotiation. }\end{array}$} \\
\hline $\begin{array}{lr}\text { Keywords } & \\
\text { Conversational } & \text { Structure; } \\
\text { Transaction; } & \text { Guide's } \\
\text { Conversational } & \text { Negotiation; } \\
\text { Exchange } & \end{array}$ & \\
\hline Support by: & \\
\hline
\end{tabular}

\section{INTRODUCTION}

The study of discourse, particularly on spoken discourse, has been carried out by numerous social scientists. Be in either formal conversation (teacher - students) or in natural setting (market transactional practice) (Robbin, 1991).The research on classroom setting, for instances, has been conducted by Jane Willis (1981), Christoph Suter (2002), Basudev Dahal (2010), Mohammad Rukanuddin, on the other hand, some carried out research in natural setting such as, McCarthy (1991) between the famous British comedy duo, Lihong Quan (2010) outside classroom between Chinese and native English, Tetsuro Chino (2011) Spontaneous Spoken Dialogue,.

Number of researches in the related field has revealed major of conversation frames according to context and field of interests. Many researches which mainly focus on covering transactional structure or rules of conversation seem to go nowhere (static) since it only tried to open the curtain without having clear contribution and putting forward significances of what it is going to render. Christopher Lind (2009) researched on repair in interaction with adult, Carmen (2011) Telephone Conversation Openings between Nativeand Nonnative Speakers, Vincenza Tudini (2003) on Conversational elements of online chatting. 
Briefly overviews, In Lembar and its surroundings, one of the most frequent inter cultural conversation encounters is guides and guests. The conversation usually occurs in the light of transactional negotiation of transportation cost. There are at least 20 active guides working for this sort of corporation. In doing transaction, very often, one to other guides have distinctive conversational structures and strategies. Some are successful but most of which are not successful, as a result transportation service which they are working for are not running properly, accordingly this research is conducted to investigate the conversation structures and strategies employed by guides and find the best ones which, latter, become standardized conversational structures and strategies in persuading and satisfying customers.

\section{METHOD}

This study is qualitative in nature, attempting to describe data, represented in the form of words. It produces findings not by means of statistical procedures or other tools of quantification. Qualitative refers to a number of research methods which involve nonnumerical data collection or explanation. Such methods include ethnography, Participant observation, unstructured interview, case study, focus group and conversation analysis. Such methods often involve the close analysis of a small amount of data rather than summarizing large amounts of data via quantitative method.

Utterances were recorded directly by a set of tape-recorders then transcribed into spoken text. Later, the recorded data were analyzed using Sinclair Coulthard analysis model of within or outside classroom discourse.The data were analyzed in terms of the four discourse units mentioned in Sinclair and Coulthard (1975): transaction, exchange,move and acts. Among these four units, exchangeand move were mainly focused. The analyzed conversations were found to be similar as well as deviant from the discourse structures suggested by Sinclair and Coulthard.This paper also paid close attention to one of spoken dscourseas mentioned by Francesca Pridham (2001) that is discourse marker.

\section{RESULT}

\section{Script 1}

Script1 is the example of transactional negotiation between Australians and tourist organizers. it happens to be a couple of australian pass by the tour organiser and willing to find out information provided by/with tourist organizers below is the conversation $A$ is organizer and $B$ is Australian (guess)

A: hallo madam, informatioin please, you just take a walk?

B: yea just walk

A: nice if you be with driver, it's a small town, it's not many things to see just shops around

B: how much would it cost?

A: eighty dollars

$\mathrm{B}$ : is that with a driver?

A: aaa... yea with a driver, it's like private car

$B$; for how long?

A: untill the last tender

B: till?

A: the last tender, it's almost 6 to aaa 7 hours

B: eee we might come back, we have to look around first,

A: okay, okay 
B: are you waiting around?

A: yea.. no problem

The first script is broken down into three exchanges, in the first exchange which can be seen in the table below. The first colum shows that regular pattern of starter is initiation, response and follow up; the function of initiation move is to open talk or chitchat by a rhetoric question, then response of initiation and the follow up is a business talk executed to lure a customer/customers.

Table 1

\begin{tabular}{|l|l|}
\hline \multicolumn{1}{|c|}{ Move } & \multicolumn{1}{c|}{ Exchange } \\
\hline Initiation & A: hallo madam, informatioin please, you just take a walk? \\
\hline Response & B: yea just walk \\
\hline Follow up & $\begin{array}{l}\text { A: nice if you be with driver, it's a small town, it's not many things to see } \\
\text { just shopsaround }\end{array}$ \\
\hline
\end{tabular}

The second exchange copes with transaction negotiation. Shifting exchange occurs as result of interesting offer; as seen in the second table below the conversation start undergoing transactional negotiation or act of asking and answering regarding tour services.

Table 2

B: how much would it cost?

A: eighty dollars

$\mathrm{B}$ : is that with a driver?

A: aaa... yea with a driver, it's like private car

B; for how long?

A: untill the last tender

B: till?

A: the last tender, it's almost 6 to aaa 7 hours

However in the last exchange, the guess commence to be disinterested as

Table 3
B: eee we might come back, we have to look around first,
A: okay, okay
B: are you waiting around?
A: yea.. no problem

In the last two moves spoken by the speaker B, there seem to be putting forward act of indirect reason not to take service from organizer. As can be seen in the statement "we might come back... and "are you waiting around" are two polite indirect strategies (negative preservation) employed by guessnot to use organiser service.

\section{Script 2}

Script 2 is transactional negotiation between a freelance guide who is offering information about Lombok and its tour and a couple of France who just landed from cruise ship. The speaker $A$ is a freelance guide while $B$ is France guess. Below is script of the transaction

A: excuseme, are you looking for a taxi driver? 
B: yes

A: we provide you like a private tour, you can go somehere aorund Lombok, I can show you on a map, if you dont mind

$\mathrm{B}$; we are waiting for friends

A; while you wait your friends, I can tell you information about lombok

B: can you explain me somewhere?

A; yes,,,step right there

B: you are the driver?

C: yes

A: does he speak english?

B: of course, he does. You will not go if the driver doesnt speak english, because I have so many drivers here, you can pick one to go with

$\mathrm{B}$ : there is no private driver speak french?

A: no

B: maybe , for the next tender they are going to arrive, because we are expecting that we wait here somewhere so we will see that.

(Walking away)

The second script is also broken down into three exchanges, in the first exchange which can be seen in the table below. The first column act as starter of conversation. It shows that there is no regular pattern of exchange. The organizer initiating conversation in terms of posing question, then response from the guess and follow up from tour provider however in the second response from the guess is somewhat different from ongoing conversation which was about informing rather, the guess respond "we are waiting for friends" which shows disinterest.

Table 4

A: excuseme, are you looking for a taxi driver?

B: yes

A: we provide you like a private tour, you can go somehere aorund Lombok, I can show you on a map, if you dont mind

$B$; but we are waiting for friends

While the second broken - down column, as it is below, acts transactional negotiation which focus on providing information and question from guess. The column shows that the regular patterns employed by both speakers are question and answer.

Table 5

A; while you wait your friends, I can tell you information about lombok

B: can you explain me somewhere?

A; yes,,,step right there

B: you are the driver?

C: yes

A: does he speak english?

B: of course, he does. You will not go if the driver doesnt speak english, because I have so many drivers here, you can pick one to go with

$\mathrm{B}$ : there is no private driver speak french?

A: no

In the last column of script 2 is depicting how the transaction end in some point and rejecting the offer by polite closing statement in another. The sentence used by the guess is indirect - rejected statement, which intentionally bring about rejection. The closing remark of "maybe, for the next tender they are going to arrive, because we are 
expecting that we wait here somewhere so we will see that" is obviously neglecting the offer of tour organizer in a very polite way.

Table 6

B: maybe , for the next tender they are going to arrive, because we are expecting that we wait here somewhere so we will see that.

(Walking away)

\section{Script 3}

It happens to be a couple of young Australian approaching the information table (tour organizer) asking for service in this case taxi service to the organizer. This transaction goes on between a guide and Australian guess. $A$ is guide and $B$ is Australian

A: information, you wanna do something?

B: we are looking for a taxi

A: right,actually we don't have a taxi here but we have a car with a driver somebody drives for you, wherever you wanna go, you can have a car in one day

B: can we do a half day?

A: possible

B: possible?

A: possible, it's like four of you and the driver speak english of course, wherever you want to go maybe you go to pottery, you go to the beach or traditional villages whatever and then driver waiting and I've got the van with air conditioning, i have no taxi but it's part of taxi

B; right, alright, how much for a half day?

A: eighty dollar for four of you

B: okay, but that's for all day, right?

A: it's all the same, because when the car gets out that's been all eighty dollar

$B$; what about australian dollar?

A: doesn matter, are you australian right?

B; yes

A: whereabout in australia do you live?

B: we live in canberra

A: ohh canberra, ohhh right not often people from canberra, may be from sydney, melbourne victoria, perth and darwin. Doesn matter eighty australian dollar, and the driver speaking English

B; okay we settle. (Writing tour voucher)

In the script 3 the conversation goes fluently and has obviously rigorous pattern. The script also breaks down into three phase: starter, transaction and closing. In the starter the pattern can be observed to have question and answer further, in the transaction the structure clearly has question and answer but in some point the organizer provides rigid information regarding tour itinerary and equipment

Table 7: Starter 
A: information, you wanna do something?

B: we are looking for a taxi

A: right,actually we don't have a taxi here but we have a car with a driver somebody drives for you, wherever you wanna go, you can have a car in one day

B: can we do a half day?

A: possible

B: possible?

Table 8: Transaction

A: possible, it's like four of you and the driver speak english of course, wherever you want to go maybe you go to pottery, you go to the beach or traditional villages whatever and then driver waiting and I've got the van with air conditioning, i have no taxi but it's part of taxi

B; right, alright, how much for a half day?

A: eighty dollar for four of you

B: okay, but that's for all day, right?

A: it's all the same, because when the car gets out that's been all eighty dollar

$\mathrm{B}$; what about australian dollar?

A: doesn matter, are you australian right?

Table 9: Closing

A: doesn matter, are you australian right?

B; yes

A: whereabout in australia do you live?

B: we live in canberra

A: ohh canberra, ohhh right not often people from canberra, may be from sydney, melbourne victoria, perth and darwin. Doesn matter eighty australian dollar, and the driver speaking English

B; okay we settle. (Writing tour voucher)

\section{CONCLUTION}

What can be observed is that the structure of guides' conversation in doing transactional negotiation is somewhat the same. Starting from so - called starter which consist of question and answer then transaction which employed question and informing and the last is closing. In the light of closing each guide has different ways.

What makes some transaction are successful while others are not is that the conversation or communication strategies in transaction. If we glance to script 3 the statement in the transaction exchange employed very comprehensive information regarding to tour itinerary and car equipment while, the other two had no such strategies. The script 1 and 2 merely focused on price without explaining the itinerary and car services extensively and they were like beating around the bush. The script 3 , even though the guess tried to convert the conversation, the guide play his role to drag the conversation back to the track as it could be seen in the transaction exchange of script 3. Moreover, if we attentively focus on the strategic closing of guide in the script 3 is somehow interesting, trying to build close relation with guess by asking nationality and pointing some information with regard to guess home country after all it worked 
out. Thus, the script 3 is standard conversation structures and strategies which should be implemented by the other guides (transaction manual).

\section{DAFTAR PUSTAKA}

[1] Brown, G. and Yule, G. 1983. Discourse Analysis. Cambridge: Cambridge University Press.

[2] Coulthard M, 2002. Advances in spoken discourse analysis. New York: Routledge

[3] Dahal B. 2010.Analysis of Spoken Discourse Patternin Nepali ELT Classes: Journal of NELTA

[4] Bou P. 2001. Conversation in Language Learning, universitat de valencia: journal on foreign

[5] Fairclough N. 2003. Analysing Discourse Textual analysis for social research, New York: Routledge

[6] Gee J P.2010. An introduction to discourse analysis: theory and method, New York: Routledge

[7] McCarthy M. 1991. Discourse Analysis for Language Teachers, Cambridge: Cambridge UniversityPress

[8] Mersley M. 2003.Conversation analysis and discourseanalysis: methods or paradigms?, London: SAGE Publications

[9] Pridham F. 2001. Conversation analysis, New York: Routledge

[10] Suter C. 2002. Analysing Spoken Discourse in the EFL classroom, Birmingham: university of Birmingham

[11] Taleghani-Nikazm C. 2010. A Conversation Analytical Study of Telephone Conversation Openings between Nativeand Nonnative Speakers, U.S.A: The University of KansasDepartment of Germanic Languages and Literatures

[12] Tetsuro C and Hiroyuki T. 2011. A New Discourse Structure Model for Spontaneous Spoken Dialogue,Kobe Japan: Toshiba Kansai Research Laboratories

[13] Urquhart C. 2000.Strategies for Conversation and Systems Analysis in Requirements Gathering: A Qualitative View of Analyst-Client Communication: NSUWorksThe Qualitative Report, Volume 4, Number $1 / 2$

[14] Wong, Olshe Jr, David. 2000.Reflections on Conversation Analysis and Nonnative Speaker Talk: An Interview with Emanuel A. Schegloff, Issues in Applied Linguistics, 11(1) 1050-4273

[15] Wooffitt R, 2005.ConversationAnalysis and Discourse Analysis A Comparative and Critical Introduction. London: SAGE Publications Ltd

[16] Zienkowski J et al. 2011. Discursive pragmatics, Amsterdam: John Benjamins B.V 